\title{
LABOR RESILIENCE: PAID MENSTRUAL LEAVE AND WOMEN'S ECONOMIC EMPOWERMENT IN INDIA
}

\author{
Rehmat Swani \\ Strawberry Fields High School
}

DOI: 10.46609/IJSSER.2020.v05i05.016 URL:https://doi.org/10.46609/IJSSER.2020.v05i05.016

\begin{abstract}
In a country with a cultural context like India, menstruation still remains a subject of taboo. Such a taboo exists across all spectrums of society, both rural and urban. Among other factors, menstruation related health issues are a major reason for the fall in female workforce participation rate. It is also a cause for discrimination at work, and women being punished for experiencing issues that are purely biological in nature. In order to achieve an equal and inclusive workplace, paid menstrual leave is an important policy measure to encourage a conversation around menstrual health and also to incentivize women to join the workforce. However, some oppose the policy based on arguments that it will lessen economic efficiency or afford women special treatment. This paper will examine the literature and arguments surrounding paid menstrual leave, and make a case for why it will increase economic efficiency and lead to a more equal society. The paper will pose recommendations for the implementation of menstrual leave policies, and emphasize on the crucial reasons why it is required.
\end{abstract}

Keywords: Labor resilience, Female labor, Menstrual leave, Women's economic empowerment

\section{INTRODUCTION}

There has been a worrisome downward trend in female labour force participation in India. Women in India face several barriers to be able to seek employment and independence, as there are still pervasive gender roles, social issues with women seeking work, etc. For poorer women, issues such as lack of basic sanitation and hygiene, and access to water also pose significant barriers. Women in India are also not educated as much as men, due to these social restrictions. This makes future opportunities for employment severely limited.

In 2017, India's female labor force participation rates (FLFPR) fell to its lowest level since Independence (Nikore, 2019). The World Bank noted that India has amongst the lowest 


\section{International Journal of Social Science and Economic Research}

ISSN: $2455-8834$

Volume: 05, Issue: 05 "May 2020"

FLFLPRs globally, with only parts of the Arab world being lesser (World Bank, 2017). For urban women, the service sector has become increasingly significant, with its share in employment rising from $35.7 \%$ in $1977-78$ to $60.7 \%$ in $2017-18$ (Nikore, 2019). In this sector, women have become concentrated in professions such as teaching and nursing, which offer only limited scope for career progression. Unlike men, neither urban nor rural women could significantly increase their presence in the secondary sector (Nikore, 2019).

A woman's decision to enter the labour force is deeply influenced by her family, marital, educational and social status. Continuing to work is a daily choice - which is rarely made by women alone (Nikore, 2019). Therefore, to bring more women into the labour force, and prevent them from dropping out of work, there is a need for targeted interventions by all relevant stakeholders - the government, private sector, media and civil society (Nikore, 2019). One issue that affects womens' ability to work in particular is menstruation. In India, there still exists a significant taboo around the subject of menstruation, where women are not educated on basic hygiene and are ostracized for that period.

For women in more educated settings as well, menstruation poses a significant barrier. While it may be a normal and painless natural process for some women, several women face debilitating conditions in relation to menstruation such as PCOS, PCOD and ovarian cysts, among others. Currently, there exists provisions for maternity related benefits and paid leave during maternity, but this is also weak. Therefore, along with reforming institutional support for maternity related issues, there also needs to be implementation of paid menstrual leave to incentivize women to participate in the formal economy. Further, corporates must also be incentivized through these schemes to hire women.

This paper will examine the existing schemes followed in relation to sexual and reproductive health, and critique the same. The paper will examine the benefits and international best practices with respect to menstrual health and paid menstrual leave, and conclude with a policy framework for India to implement similar measures as other developed nations to increase efficiency, as well as reduce gender discrimination in the workplace and in employment.

\section{BACKGROUND}

Less than 19 per cent of the new employment opportunities generated in India's 10 fastest growing occupations were taken up by women (Kapsos, 2014). Despite increases in primary and secondary educations, women have systematically lost out on opportunities in fast growing sectors owing to an increasing demand for technically skilled labor, and men having higher tertiary educational and vocational training levels (Kapsos, 2014; Nikore, 2019). The deeprooted segregation of gender-specific activities further results in a lack of family support for 


\section{International Journal of Social Science and Economic Research}

ISSN: $2455-8834$

Volume: 05, Issue: 05 "May 2020"

women's careers and prevents Indian women from participating in the workforce (Kapsos, 2014).

Currently, corporate policies and schemes in India are only focused on the aspect of maternity. The Maternity Benefits Act mandates a certain period of paid maternity leave for women, during pregnancy and post the delivery of the child. However, even such schemes are lacking. The Maternity Act (Amendment) 2016 places the entire cost burden of women's leave on employers disincentivizing women's hiring in the formal sector (Nikore, 2019). Further, less than $1 \%$ of the government's budget is allocated for gender related policies, showing the paucity of resources available for policy action (Nikore, 2019). To address this issue, the government is considering the introduction of the Maternity Leave Incentive Scheme whereby seven weeks' wages would be reimbursed to employers who employ women workers with a wage ceiling up to INR $15,000.00$ a month and provide them maternity benefit of 26 weeks paid leave (Pathak, et al, 2018).

There has been some level of discussion and debate surrounding paid menstrual leave in India. The Menstruation Benefit Bill tabled by a Member of Parliament from Arunachal Pradesh, but has not rendered any concrete results or further discussion surrounding its implementation (Prasad, 2018). Several countries have introduced a menstrual leave provision for their employees. As early as 1947, Japan passed a law allowing women with debilitating periods to take days off (Prasad, 2018). Similarly, in South Korea, women were granted menstrual leave from the year 2001 onwards. Companies like Nike have also adopted similar policies. Such policies also exist in Indonesia, South Korea and Taiwan (Prasad, 2018). There are no such policies in either Europe or the United States, but efforts for its implementation have been heavily debated. In Zambia, as of 2015, women are legally entitled to a day off each month due to their menstrual leave policy, known as "Mother's Day." If a woman employee is denied of this policy, she can rightfully prosecute her employer (Worley, 2017). The southern African nation has enshrined the practice into its Labour laws.

Interestingly, in India, the Bihar Government has been offering two days of period leave to women employees since 1992 (Prasad, 2018). Women can decide which two days of the month they would like to take off without having to provide any justification for doing so. In the recent past, a handful of private companies like the Mumbai-based media firm, Culture Machine, have also started offering menstrual leave (Prasad, 2018).

In different parts of the world, there has been a great level of debate regarding the advantages and disadvantages of paid menstrual leave as a policy. Those who are not in favour of the policy argue that it will only prejudice employers against hiring women and lead to their alienation at 


\section{International Journal of Social Science and Economic Research}

Volume: 05, Issue: 05 "May 2020"

work (Prasad, 2018; Maguire et al, n.d). They also believe that most women are capable of functioning at full capacity even during their periods and for the handful of women who do suffer debilitating symptoms, the existing sick leave option is adequate (Prasad, 2018). However, those in favour of the policy point to several studies which demonstrate the debilitating effects of menstruation that some women face. The average blood loss during menstruation is $30-40 \mathrm{ml}$; heavy menstrual bleeding (HMB) is defined as blood loss of $80 \mathrm{ml}$ or more per cycle (Maguire et al, n.d). HMB can be caused by abnormal blood clotting, disruption of normal hormonal regulation or other disorders, such as fibroids, polyps, endometriosis and adenomyosis (Maguire et al, n.d). Primary dysmenorrhea (PD) is menstrual pain experienced by women with normal pelvic anatomy and is most common amongst young women (Maguire et al, n.d).

Therefore, even though there are certain concerns with respect to menstrual leave being patronizing or disrespectful to women, it will benefit a large percentage of women and ensure that they are able to equally and fully participate in the workforce. Further, it serves to reduce the taboo surrounding menstruation and encourage dialogue in a formal setting. It will discourage discrimination of women, if they are not able to optimally perform due to menstruation related health conditions. While one can certainly argue against the need for a period leave policy, the problem with these arguments is that they only perpetuate age old biases and do little to take the gender equity discourse forward in a constructive and balanced manner (Prasad, 2018).

\section{DISCUSSION}

In India, there is an extra need for such a policy given the cultural stigma that exists, far more than western countries. Further, the gender pay gap remains more pervasive in India than elsewhere. Therefore, even paid menstrual leave would not compensate for their substantially lower wages. The World Economic Forum's 'Global Gender Gap Report' ranks India a dismal 136 out of 144 countries for parity in wages between men and women (Belliappa, 2018). However, such a policy would be a much needed start and step in the right direction. There is a misconception among several opponents of this policy that it will lead to inefficiency and disincentivize the hiring of women and fair treatment (Belliappa, 2018).

With more participation of those who constitute half of the workforce, it is to follow quite naturally that there will be increased efficiency. Severe menstrual pain can have a significant impact on academic and employment participation (Maguire et al, n.d). Studies show that about $30-50 \%$ of young women miss school or work at least once per cycle due to PD (Maguire et al, n.d). Even when school or work is attended, the presence of pain can affect concentration leading to poor performance and productivity (Maguire et al, n.d). Women who experience adverse menstrual symptoms report having a significantly lower quality of life than the general female 


\section{International Journal of Social Science and Economic Research}

ISSN: $2455-8834$

Volume: 05, Issue: 05 "May 2020"

population. Studies show that HMB and dysmenorrhea that disrupt the usual routine is perceived as having a major impact on quality of life (Maguire et al, n.d). The effects of lost productivity and academic achievement extend beyond individual costs. Workplaces incur significant costs from reported rates of absenteeism and reduced performance due to menstrual symptoms (Maguire et al, n.d). Absenteeism due to HMB is estimated to annually costs US\$12 billion, though this may be an underestimate as the costs of presenteeism were excluded from calculations (Maguire et al, n.d).

Several studies indicate that the efficiency levels of women are low during menstruation. Therefore, availing a leave during the menstrual cycle would not affect the productivity of the organisation and the economy (Chaitra V, 2019). Emphasis must be on labour productivity and the quality of output, rather than simply measuring productivity based on the hours of work (Chaitra V, 2019). Research from Australia has indicated that 'menstrual flexibility' is an economically viable alternative (Chaitra V, 2019). Studies have shown that women who are able to take time off during their period of menstruation increase their productivity and make up for the time on other day, which balances and in fact increases efficiency as they have had time to recover (Chaitra V, 2019). Therefore, it is important to include methods of improving female labor force participation by incorporating the same in India and other developing countries.

Doctors across the globe acknowledge that dysmenorrhoea or menstrual cramps can be as painful as heart attacks (Chaitra V, 2019). However, some women do experience very little or no pain during their menstruation and it is inappropriate for such women who go through less painful periods, to generalise the experience for other women. This does not serve to further the cause of equality for all women, accounting for their biological differences. Many symptoms can be alleviated with rest or by avoiding physically demanding tasks (the amount of rest required differs from one woman to another) (Belliappa, 2018). It is noteworthy that women who do not suffer from chronic conditions do not necessarily have equally painful periods during every cycle (Belliappa, 2018). Some cycles could be more painful than the others for various reasons including stress, changes in hormonal levels and diet (Belliappa, 2018).

\section{CONCLUSION}

Menstrual health impacts across a broad range of policy areas including education, economic activity, justice/equality and public health (Maguire et al, n.d). Future policy measures necessarily have to be focused on the inclusion of paid menstrual leave alongside maternity leave. This is crucial to making a marked difference in women's participation in the formal economy, especially in India, where menstruation remains a taboo despite the socio-economic status or educational levels of women. 


\section{International Journal of Social Science and Economic Research}

ISSN: $2455-8834$

Volume: 05, Issue: 05 "May 2020"

Workplaces need to be inclusive of women's bodies not only for ethical reasons but also to create a more engaged and productive workforce and the menstrual leave debate provides a unique opportunity in this regard (Belliappa, 2018). However, a policy on menstruation needs to be created with careful thought and planning as part of an employer's commitment to diversity and inclusivity and not in isolation (Belliappa, 2018). The government can also help by supporting the development of policies, programme and practice that enable women to minimise risk factors for menstrual disorders, recognise abnormal symptoms and seek healthcare at an early stage (Maguire et al, n.d). Given the impacts of menstrual symptoms on women's participation in the workplace and the debate surrounding menstrual leave policies, there is an opportunity to highlight this topic and tackle the issues. Policymakers and stakeholders should facilitate an open debate on the management of menstruation in the workplace (Maguire et al, n.d).

Over the last 70 years, women have remained on the margins of the formal economy dutifully supporting doctors as nurses, master weavers as assistants, and farmers as casual agricultural labourers (Nikore, 2019). It is high time women were brought to the frontlines of workforce participation, and given their fair share of the economic pie, as well as treated equally and with dignity.

\section{REFERENCES}

Belliappa, J., (2018), "Menstrual Leave Debate: Opportunity to Address Inclusivity in Indian Organizations”, Indian Journal of Industrial Relations, Vol.53 Issue 4

Chaitra, V. (18 Jan 2019), “'Menstrual leave' an ignored issue?”, Deccan Herald, Retrieved from https://www.deccanherald.com/opinion/in-perspective/precarious-workers-left-inthe-lurch-820653.html

Kapsos, S., (2014), "Why is female labour force participation declining so sharply in India?", ILO Research Paper No.10, International Labour Office

Maguire et al, (n.d), "Women and Menstruation in the EU”, Eurohealth Policy Brief

Nikore, M., (2019), "Where are India's working women? The fall and fall of India's female labour participation rate", London School of Economics South Asia Blog, Retrieved from https://blogs.lse.ac.uk/southasia/2019/10/22/where-are-indias-working-women-the-falland-fall-of-indias-female-labour-participation-rate/ 
Pathak et al, (2018), "The Maternity Leave Incentive Scheme, 2018: Blessing in the Pipeline for Working Women in India", India Corporate Law, Retrieved from https://corporate.cyrilamarchandblogs.com/2018/11/maternity-leave-incentive-scheme2018-blessing-pipeline-working-women-india/

Prasad, U., (2018), “India needs a menstrual leave policy”, Hindu Business Line, Retrieved from https://www.thehindubusinessline.com/opinion/india-needs-a-menstrual-leavepolicy/article24105589.ece

Worley, W., (2017), "The country where all women get a day off because of their period", Independent, Retrieved from https://www.independent.co.uk/news/world/africa/zambiaperiod-day-off-women-menstruation-law-gender-womens-rights-a7509061.html 